\title{
A NECESSIDADE DE FUNDAMENTAÇÃO DAS DECISÕES
}

\author{
Alexandre Gindler de Oliveira \\ Guilherme Barnabé Mendes Oliveira
}

\section{INTRODUÇÃO}

Com o advento do Novo Código de Processo Civil (NCPC) e, por conseguinte, com as inovações por ele trazidas, os operadores do direito, incansáveis questionadores de dogmas, debruçaram-se sobre os temas aparentemente polêmicos que, a partir de então, passaram fazer parte do ordenamento jurídico pátrio. Dentre tantas mudanças, para o presente estudo elegeu-se uma que, apesar de ter sido expressamente incorporada às frias palavras da lei, há tempos vem assombrando o sistema processual brasileiro: a necessidade de fundamentação das decisões.

Com efeito, tal questão, desde a promulgação da Constituição Federal atual, ganhou status de garantia constitucional e, assim, conquistou espaço nas discussões acadêmicas, judiciais e administrativas acerca de direito processual. Sua ausência passou a ser interpretada como verdadeira negativa de prestação jurisdicional, bem como o devido processo legal, além do contraditório, passou a contar com mais uma exigência: o direito da parte em ser ouvida, ou melhor, o direito da parte de ver seus argumentos considerados (positiva ou negativamente) pela autoridade julgadora.

Paralelamente à aplicação desse princípio nos processos judiciais, qualquer que seja sua natureza, não se pode deixar de notar que, pela aplicação subsidiária ou supletiva das regras processuais aos processos administrativos, comumente manejados na seara tributária, as decisões também desses incidentes contam com essa 
exigência para se sustentarem validamente no sistema em que estão inseridas. A defesa, portanto, da fundamentação das decisões como base de suas respectivas validades - seja em processo judicial, seja em processo administrativo - consubstancia, em suma, o objetivo deste estudo.

\section{O DEVER DE FUNDAMENTAÇÃO}

\subsection{Constituição Federal de 1988}

O direito é um sistema de normas jurídicas válidas que regulam a conduta dos homens, sendo certo que o fundamento de validade de uma norma é a validade de outra, ou seja, uma norma apenas é válida por possuir suporte em uma norma superior, até se chegue à norma hipotética fundamental que pressupõe a validade de todo o sistema. ${ }^{1}$ E como norma fundamental se tem a Constituição Federal, a qual legitima tanto as leis quanto as normas individuais e concretas.

Dentro dessa cadeia normativa escalonada, na qual a Constituição está no topo, existem normas superiores dentro de seu próprio corpo, as quais, por conferirem as diretrizes do ordenamento jurídico, são chamadas de princípios. Segundo o ensinamento do professor Paulo de Barros Carvalho, ${ }^{2}$

os princípios aparecem como linhas diretivas que iluminam a compreensão de setores normativos, imprimindo-lhes caráter de unidade relativa e servindo de fator de agregação num dado feixe de normas. Exercem eles uma reação centrípeta, atraindo em torno de si regras jurídicas que caem sob seu raio de influência e manifestam a força de sua presença.

$\mathrm{Na}$ mesma linda, o professor Roque Antonio Carrazza ${ }^{3}$ ensina que

princípio jurídico é um enunciado lógico, implícito ou explícito, que, por sua grande generalidade, ocupa posição de preeminência nos vastos quadrantes do Direito e, por isso mesmo, vincula, de modo inexorável, o entendimento e a aplicação das normas jurídicas que com ele se conectam.

1 KELSEN, Hans. Teoria pura do Direito. 4. ed. São Paulo: Martins Fontes, 1994. p. 215

2 CARVALHO, Paulo de Barros. Curso de Direito Tributário. 25. ed. São Paulo: Saraiva, 2013. p. 158.

3 CARRAZZA, Roque Antonio. Curso de Direito Constitucional Tributário. 20. ed. São Paulo: Malheiros, 2004. 
Dentre os diversos princípios existentes na Magna Carta, deve-se destacar, neste particular estudo, o princípio da fundamentação das decisões judiciais, o qual pode ser apreendido pela leitura do art. 93, inciso IX, da Constituição Federal de 1988 (CF/88), que dispõe que "todos os julgamentos dos órgãos do Poder Judiciário serão públicos, e fundamentadas todas as decisões, sob pena de nulidade". A norma constitucional determina, portanto, que uma decisão não fundamentada é nula, de forma que o intérprete da lei, se proferir uma decisão desse jaez, estará agindo fora do manto do Estado Democrático de Direito. E a não observância de tal linha diretiva é apenada, pela própria norma fundamental, com respectiva incapacidade (da norma concreta e individual) de atingir validade e eficácia junto a seus sujeitos

Como se não bastasse, na CF/88 estão as principais garantias fundamentais de todo e qualquer cidadão, lá estabelecidas, dentre outros objetivos, com o fito de se constituir uma sociedade justa (art. $3^{\circ}$, inciso I). Entre os incisos do art. $5^{\circ}$, destaca-se que, no Brasil, não haverá juízo ou tribunal de exceção (inciso XXXV), ou seja, vigerá o Estado Democrático de Direito, o qual se estrutura no monopólio da violência exercida pelo Estado e, consequentemente, no seu dever/poder de exercer a jurisdição, a qual, por sua vez, pressupõe a clareza daquilo que se decide.

Assim, não se pode perder de vista que uma decisão de mérito, seja em processo judicial, seja em processo administrativo, por consubstanciar uma suposta solução provocada por sujeitos inseridos em insuperável conflito de interesses, é uma importante manifestação do Estado: é o verdadeiro exercício do monopólio da violência, mostrando-se, assim, claramente necessário que o agente que a profira aclare como chegou a determinada conclusão para o caso concreto para si apresentado. Agir sem essa clareza é agir de maneira totalitária e, assim, sem legitimidade, na medida em que atua fora da competência emanada por todo o povo (parágrafo único do art. $1^{\circ}$ da $\mathrm{CF} / 88$ ).

Além das decisões necessitarem ser claras, destaca-se que elas devem ser construídas sobre um contraditório efetivo (art. $5^{\circ}$, inciso LV, da CF/88), o que, mais que o direito de manifestação, representa o notório direito de ser ouvido. Sobre o reconhecimento judicial desse direito de se fazer ouvir, vale destacar a conhecida decisão do Supremo Tribunal Federal (STF) que consignou que "o exercício pleno do contraditório não se limita à garantia de alegação oportuna e eficaz a respeito de fatos, mas implica a possibilidade de ser ouvido também em matéria jurídica" (Pleno. MS 24.268-0-MG. Rel. Min. Gilmar Mendes, DJ: 17 set. 2004). 
Nessa decisão, o Ministro Gilmar Mendes explica que

há muito vem a doutrina constitucional enfatizando que o direito de defesa não se resume a um simples direito de manifestação no processo. Efetivamente, o que o constituinte pretende assegurar - como bem anota Pontes de Miranda - é uma "pretensão à tutela jurídica (Comentário à Constituição de 1967/69, tomo V, p. 234)" e que "não é outra a avaliação do tema no direito constitucional comparado". Apreciando o chamado "Anspruch auf recbtliches Gehör" (pretensão à tutela jurídica) no direito alemão, assinala o Bundesverfassungsgericht que essa pretensão envolve não só o direito de manifestação e o direito de informação sobre o objeto do processo, mas também o direito de ver os seus argumentos comtemplados pelo órgão incumbido de julgar (Cf. Decisão da Corte Constitucional alemã - BverfGE 70, 288-293; sobre o assunto, ver também, Pieroth e Schlink, Grundrechte - Staatsrecht II, Heidelberg, 1988, p. 281; Battis, Ulrich, Gusy, Christoph, Einfuhrung in das Staatsrecht, $3^{a}$ edição, Heidelberg, 1991, p. 363-364).

Conclui, assim, o Ministro Gilmar Mendes que

sobre o direito de ver os seus argumentos comtemplados pelo órgão julgador (Recht auf Berücksichtigung), que corresponde, obviamente, ao dever do juiz ou da Administração de a eles conferir atenção (Beachtenspflicht) pode-se afirmar que envolve não só o dever de tomar conhecimento (Kenntnisnabmepflicht), como também o de considerar, séria e detidamente, as razões apresentadas (Erwägungsflicht) (Cf. Dürig/Assmann, in: Maunz-Dürig, Grundgesetz-Kommentar, Art. 103, vol. IV, no 97). É da obrigação de considerar as razões apresentadas que deriva o dever de fundamentar as decisões (Decisão da Corte Constitucional - BverfGE 11, 218 (218)/Cf. Dürig/Assmann, in: Maunz-Dürig, Grundgesetz-Kommentar, Art. 103, vol. IV, no 97).

Sobre o tema, ainda, temos as sábias palavras do doutrinador Alexandre Freitas Câmara, ${ }^{4}$ para o qual

sempre foi da cultura do processo civil brasileiro admitir-se a prolação de decisões fundadas em argumentos de direito que não tivessem sido submetidos a debate prévio. Era o que se extraía da clássica parêmia da mibi factum, dabo

4 CÂMARA, Alexandre Freitas. O Novo Processo Civil Brasileiro. São Paulo: Atlas, 2015. p. 11-12. 
tibi ius ("dá-me os fatos que te darei o direito"). Era o que tradicionalmente se acreditou que a incumbência das partes era apresentar ao juízo os fatos da causa, cabendo ao órgão jurisdicional estabelecer o direito aplicável. Ocorre que esta é uma forma de atuar incompatível com o Estado Constitucional, já que presa à ultrapassada ideia de que o processo serve apenas para que o Estado dê solução às causas que lhe são submetidas, construindo os resultados de forma solipsista. Este juiz solipsista, egoísta, que constrói a decisão judicial sozinho, é incompatível com o Estado Democrático de Direito, o qual exige que o exercício do poder estatal se dê de forma coparticipativa, já que a participação da sociedade é um dos elementos integrantes dessa forma de Estado expressamente estabelecida pela Constituição da República. Assim só é constitucionalmente legítima (ou, dito de outro modo, só é democrática) a decisão judicial construída em contraditório por todos os participantes do processo, os quais incumbe debater todo e qualquer possível fundamentação da decisão judicial.

Percebe-se, portanto, que o princípio do dever de fundamentação, além de expresso no mencionado art. 93, inciso IX, da CF/88, é construído também, de maneira implícita, pelos princípios do Estado Democrático de Direito, sendo manifestado, basicamente, por meio de decisões claras e derivadas de um contraditório efetivo, cuja dialeticidade transcende os fatos para atingir, igualmente, as teses jurídicas.

\subsection{Novo Código de Processo Civil}

Embora a Constituição Federal seja hierarquicamente superior às leis e às decisões judiciais, na prática, infelizmente, é muito comum encontrar graves distorções, em que se privilegia a aplicação do direito mais próximo em detrimento das determinações constitucionais. Não é difícil encontrar, por exemplo, especialmente em repartições tributárias municipais, a prevalência de portarias sobre as garantias fundamentais. Diante dessa constatação empírica, cada vez mais se tem encontrado normas inferiores com verdadeiras reproduções do texto de normas superiores, deixando inconteste, aos respectivos súditos, que os princípios constitucionais estão efetivamente incorporados e respeitados.

Neste sentido, vê-se a reprodução ipsi literis do supramencionado art. 93, inciso IX, da CF/88 no art. 11 do NCPC: "todos os julgamentos dos órgãos do Poder Judiciário serão públicos, e fundamentadas todas as decisões, sob pena de 
nulidade". Nesse documento legislativo, além de se verificar o respeito ao modelo constitucional de processo civil, percebe-se a sua constatação de maneira explícita, por exemplo, nas normas fundamentais do processo civil (título único do livro I), as quais criam os chamados princípios legais, consubstanciados pela reprodução, muitas vezes, dos princípios constitucionais.

Além de manifestado no art. 11, o princípio da fundamentação das decisões também pode ser compreendido, por exemplo, pela leitura dos art. $371^{5}$ e $489^{6}$ do NCPC. Ou seja, além de o juiz ter de apreciar as provas constantes nos autos e indicar as razões da formação de seu convencimento, as suas decisões devem respeitar um mínimo de fundamentação e não incidir em uma das hipóteses do $\mathbb{S}$ $1^{\circ}$ do art. 489, o qual serve como regulamentação do princípio de fundamentação.

Sobre o assunto, a professora Aurora Tomazini de Carvalho ${ }^{7}$ explica que

até o advento do novo Código, mais especificamente, do art. 489, \$1 $\$ 1^{\circ}$ (objeto deste estudo) não existia, no ordenamento jurídico brasileiro, dispositivo regulamentando o que se considerada, para fins de anulação ou revisão, uma

5 "Art. 371. O juiz apreciará a prova constante dos autos, independentemente do sujeito que a tiver promovido, e indicará na decisão as razões da formação de seu convencimento."

6 "Art. 489. São elementos essenciais da sentença: I - o relatório, que conterá os nomes das partes, a identificação do caso, com a suma do pedido e da contestação, e o registro das principais ocorrências havidas no andamento do processo; II - os fundamentos, em que o juiz analisará as questões de fato e de direito; III - o dispositivo, em que o juiz resolverá as questões principais que as partes the submeterem.

$\S 1^{\circ}$ Não se considera fundamentada qualquer decisão judicial, seja ela interlocutória, sentença ou acórdão, que: I - se limitar à indicação, à reprodução ou à paráfrase de ato normativo, sem explicar sua relação com a causa ou a questão decidida; II - empregar conceitos juridicos indeterminados, sem explicar o motivo concreto de sua incidência no caso; III - invocar motivos que se prestariam a justificar qualquer outra decisão; IV - não enfrentar todos os argumentos deduzidos no processo capazes de, em tese, infirmar a conclusão adotada pelo julgador; $\mathrm{V}$ - se limitar a invocar precedente ou enunciado de súmula, sem identificar seus fundamentos determinantes nem demonstrar que o caso sob julgamento se ajusta àqueles fundamentos; VI - deixar de seguir enunciado de súmula, jurisprudência ou precedente invocado pela parte, sem demonstrar a existência de distinção no caso em julgamento ou a superação do entendimento. § $2^{\circ}$ No caso de colisão entre normas, o juiz deve justificar o objeto e os critérios gerais da ponderação efetuada, enunciando as razões que autorizam a interferência na norma afastada e as premissas fáticas que fundamentam a conclusão. $\S 3^{\circ} \mathrm{A}$ decisão judicial deve ser interpretada a partir da conjugação de todos os seus elementos e em conformidade com o princípio da boa-fé."

7 CARVALHO, Aurora Tomazini de. Direito Tributário e os novos horizontes do processo. São Paulo: Noeses, 2015. p. 144. 
"decisão não fundamentada" (uma das funções deste novo dispositivo, no nosso entender).

Na mesma linha, o já citado doutrinador Alexandre Freitas Câmara ${ }^{8}$ considera que

o CPC exige, concretizando o princípio constitucional, uma fundamentação substancial das decisões. Não se admite a prolação de decisões falsamente motivadas ou com "simulacro de fundamentação". É o que se dá nos casos arrolados no $\$ 1^{\circ}$ do art. 489 , o qual enumera uma série de casos de falsa fundamentação, as quais são expressamente equiparadas às decisões não fundamentadas (FPPC, enunciado 303: "As hipóteses descritas nos incisos do $\$ 1^{\circ}$ do art. 489 são exemplificativas”).

Percebe-se, portanto, da leitura do mencionado $\int 1^{\circ}$ do art. 489 que uma decisão será considerada não fundamentada quando não explicar (incisos I e II), justificar (inciso III), identificar (inciso V) e demonstrar (inciso VI), ou seja, aquelas que não são claras ou que são prolatadas sem observância ao contraditório efetivo (inciso IV).

Assim, não se pode considerar uma decisão fundamentada a que "se limitar à indicação, à reprodução ou à paráfrase de ato normativo, sem explicar sua relação com a causa ou a questão decidida" (inciso I), ou seja, aqueles atos decisórios que se limitam a indeferir determinado pedido de tutela de urgência por considerar ausentes a probabilidade do direito e o perigo de dano são atos supostamente nulos, já que falsamente fundamentados, pois pecam, principalmente, pela falta de identificação das razões de decidir com os pedidos concretamente lançados.

Também se pode considerar sem fundamentação a decisão que "empregar conceitos jurídicos indeterminados, sem explicar o motivo concreto de sua incidência no caso" (inciso II). Ou seja, todas aquelas que meramente deferem ou indeferem pedidos sem enfrentar adequadamente o motivo pelo qual foram provocadas (como "indefiro o levantamento, haja vista o interesse público" ou "indefiro, posto que desproporcional a medida") são carecedoras de fundamentação, mostrando-se totalitárias e, portanto, em desconformidade com o Estado Democrático de Direito. De igual forma, tem-se por não fundamentada a decisão que

8 CÂMARA, Alexandre Freitas. O Novo Processo Civil Brasileiro. São Paulo: Atlas, 2015. p. 14. 
"invocar motivos que se prestariam a justificar qualquer outra decisão" (inciso III), já que prescinde, assim, da necessária identificação do caso concreto submetido à análise do julgador.

Será considerada nula, ainda, a decisão que "não enfrentar todos os argumentos deduzidos no processo capazes de, em tese, infirmar a conclusão adotada pelo julgador" (inciso IV), na medida em que lacônica quanto à formulação da síntese, em cotejo de tese e antítese.

Conforme exposto, mais que o direito a um devido processo legal, mais até que o direito de petição, o jurisdicionado, em verdade, tem o direito de ser ouvido, isto é, de ter todos os seus argumentos lidos e considerados, um a um. E, mais, segundo Câmara'

é direito da parte ver na decisão que lhe é desfavorável a exposição dos motivos que levaram à rejeição de todos os fundamentos que suscitou em seu favor. Só assim se poderá afirmar que sua participação no processo de formação da decisão foi relevante, que ela foi ouvida (ainda que não tenha sido atendida) e, portanto, que foi plenamente respeitada sua participação em contraditório.

Nesse sentido, não tem validade, também, a decisão que "se limitar a invocar precedente ou enunciado de súmula, sem identificar seus fundamentos determinantes nem demonstrar que o caso sob julgamento se ajusta àqueles fundamentos" (inciso V). Ora, com base nesse dispositivo, a obrigação de identificar o caso concreto com o precedente ou súmula se tornou exigível, tolhendo, acertadamente, menções genéricas e infundadas de ementas ou súmulas até então utilizadas para expressar convicções preestabelecidas dos interpostos julgadores.

Por fim, será considero nulo todo ato decisório que "deixar de seguir enunciado de súmula, jurisprudência ou precedente invocado pela parte, sem demonstrar a existência de distinção no caso em julgamento ou a superação do entendimento" (inciso VI). Em outras palavras, para que se afaste súmula, jurisprudência ou precedente de determinado caso concreto, terá o julgador que se valer do distinguishing (demonstração da distinção do caso concreto com súmula, jurisprudência ou precedente apontado) ou do overrruling (demonstração de que o entendimento apontado em súmula, jurisprudência ou precedente apontado está superado).

9 CÂMARA, Alexandre Freitas. O Novo Processo Civil Brasileiro. São Paulo: Atlas, 2015. p. 15. 


\subsection{Duração razoável do processo}

Pode-se afirmar, em resumo, que a fundamentação de uma decisão é a demonstração precisa dos motivos que levaram o julgador a proferi-la da maneira escolhida. É a superação de fundamentações formais, fictas e falaciosas e a verificação da verdadeira justificativa aplicada ao caso concreto. O NCPC busca, assim, o aperfeiçoamento das decisões judiciais, regulamentando, para tanto, o dever de fundamentação.

Nessa toada, além da alteração sensível dos notórios elementos essenciais da sentença, a inovação legislativa trouxe ainda mudança importante no que se refere ao relatório dos atos decisórios, que deverá conter a correta identificação do caso.

Além dos novos princípios processuais (como o da cooperação, estabelecido no art. $6^{\circ}$ do NCPC), é de se destacar que as novas normas processuais, já vigentes atualmente, contribuíram para razoável modificação do sistema anterior. Ao determinar, por exemplo, que se identifique o caso concreto no relatório das sentenças judiciais, o legislador obriga os intérpretes da lei a delimitarem a causa de pedir ao decidir, muito além, portanto, do mero pedido.

Esse dever de identificação da causa de pedir e a respectiva regulamentação da fundamentação são de extrema importância para o sucesso das novas relações jurídicas processuais, especialmente porque baseadas, a partir de agora, na aplicação de precedentes como delineadores direitos e deveres processuais. Neste sentido, a professora Aurora Tomazini de Carvalho ${ }^{10}$ brilhantemente alerta que

quando o aplicador produz norma individual e concreta, resultante da aplicação, ele diz qual é o fato e diz qual é o direito. A linguagem produzida positiva suas escolhas, por meio dela temos acesso à decisão, o que possibilita o controle de sua valoração. Como já vimos, a tomada de posição sobre o fato e sobre a norma a ser aplicada é um ato valorativo, mas não desregrado. De acordo com os critérios estabelecidos pelo próprio sistema é vedado ao aplicador constituir o fato jurídico com base em elementos diversos dos constantes na linguagem das provas admitidas, assim como também lhe é vedado construir a norma a ser aplicada sem a devida identificação de lei (suporte físico do direito positivo). O controle da decisão é

10 CARVALHO, Aurora Tomazini de. Direito Tributário e os novos horizontes do processo. São Paulo: Noeses, 2015. p. 157. 
feito pela objetivação dos valores constantes no ato de aplicação, por isso, a necessidade de sua fundamentação.

Julgar dessa maneira - isto é, sem elucidar adequadamente, por meio de um contraditório efetivo, as razões pela qual se chegou à conclusão de que determinado pedido procede ou não - é proferir decisão nula. Assim, até mesmo pelo próprio impedimento que tal ato causa na apreciação de mérito nas instâncias superiores, sua reforma é de mister, com a determinação, por essas instâncias, de que novo ato decisório seja proferido, desta vez de forma legal, constitucional e conforme o Estado Democrático de Direito.

Percebe-se nessa constatação, então, que o dever de fundamentação das decisões está intimamente ligado ao princípio da duração razoável do processo, o qual compreende, em essência, a busca por atos praticados de maneira mais robusta, a fim de que sejam verdadeiramente eficazes, evitando reformas desnecessárias e obstáculos formais ao objetivo principal: a distribuição da justiça.

\section{ENUNCIADOS DA ESCOLA NACIONAL DE FORMAÇÃO E APERFEIÇOAMENTO DE MAGISTRADOS}

Com o início de vigência do NCPC, a aplicação de muitas de suas inovações inquietava os operadores do direito. Nada mais normal, já que é da natureza humana a preocupação com o desconhecido e a desconfiança de seus desdobramentos.

Nesse cenário, a Escola Nacional de Formação e Aperfeiçoamento de Magistrados (Enfam), com especial intuito de acalmar os ânimos e evitar distorções interpretativas, antecipou-se e, por meio de preciosos estudos, construiu e divulgou seus enunciados: uma verdadeira orientação para uniforme aplicação da nova legislação dentro de um sistema concreto preexistente. Assim, com segurança, grande parte dos julgadores tem pautado suas decisões nesses enunciados, de forma que, por relação direta com o presente tema, uma detida análise de alguns deles é imprescindível para este estudo.

\subsection{Enunciado 9}

O Enunciado 9 assim dispõe:

É ônus da parte, para os fins do disposto no art. 489, $₫ 1^{\circ}$, V e VI, do CPC/2015, identificar os fundamentos determinantes ou demonstrar a existência de 
distinção no caso em julgamento ou a superação do entendimento, sempre que invocar jurisprudência, precedente ou enunciado de súmula.

Embora se tenham, com esse pronunciamento, reconhecido as exigências legais de fundamentação das decisões, a ideia dos intérpretes da lei para fazer valer a norma cogente do art. 489 do NCPC foi delegar às partes envolvidas em processo litigioso o ônus de demonstrar a ocorrência de distinguishing ou de overrruling. No entanto, apesar de recomendável, tal delegação não consubstancia a melhor interpretação dos dispositivos legais, principalmente porque não há lacuna que eventualmente possa ser preenchida por meio deste ato de mera orientação.

O NCPC, nessa determinação, é claro e não admite emendas: cabe ao julgador prezar pela demonstração da distinção do caso concreto com súmula, jurisprudência ou precedente apontado, bem como pela demonstração de que o entendimento em súmula, jurisprudência ou precedente apontado está superado.

\subsection{Enunciado 10}

O Enunciado 10 assim dispõe: "A fundamentação sucinta não se confunde com a ausência de fundamentação e não acarreta a nulidade da decisão se forem enfrentadas todas as questões cuja resolução, em tese, influencie a decisão da causa".

Em brilhante interpretação, esse enunciado consegue deixar explícita a essência do mens legis que originou o Código de Processo Civil (CPC): o dever de fundamentação deve abarcar o contraditório efetivo, levando-se em conta tese e antítese para, em conclusão, construir a síntese.

\subsection{Enunciado 11}

O Enunciado 11 assim dispõe: "Os precedentes a que se referem os incisos $\mathrm{V}$ e VI do $\int 1^{\circ}$ do art. 489 do CPC/2015 são apenas os mencionados no art. 927 e no inciso IV do art. 332".

A adoção de precedentes como diretrizes norteadoras das decisões é relevante mudança trazida pelo NCPC. Não obstante, até pela formação jurídico-cultural brasileira fundada no Civil Law (isto é, no direito positivo), há de se amadurecer a compreensão de um sistema baseado em precedentes judiciais (Common Law) antes de aplicar, irrestritamente, os incisos V e VI do $\int 1^{\circ}$ do art. 489 do NCPC.

Justamente com esse intuito sobreveio o enunciado sob comento. Ao qualificar determinadas decisões como "precedentes", busca-se a uniformização da 
jurisprudência dos tribunais superiores, evitando-se a pulverização de decisões de instâncias inferiores, cujos entendimentos, atualmente, apresentam grande campo de variação. Todavia, uma vez alcançada suficiente maturidade, não se recomenda que essa interpretação remanesça inalterada. Diversas outras hipóteses, em tese, poderão num futuro próximo valer como precedentes judiciais, desde que, claro, construídos pelos princípios da isonomia e da segurança jurídica, respeitando o devido processo legal.

\subsection{Enunciado 12}

O Enunciado 12 assim dispõe: "Não ofende a norma extraível do inciso IV do $\S 1^{\circ}$ do art. 489 do CPC/2015 a decisão que deixar de apreciar questões cujo exame tenha ficado prejudicado em razão da análise anterior de questão subordinante".

Ao que parece, a aplicação irrestrita dessa orientação interpretativa pode causar o aumento de um fenômeno que, com a reforma legislativa, se estava tentando combater: a proliferação de decisões prêt-à-porter, isto é, decisões que de tão vagas e genéricas podem ser utilizadas em todo e qualquer caso. Apesar disso, é mais salutar acreditar que, ao contrário, a verdadeira intenção dessa recomendação seja garantir a razoável duração do processo, sem que o julgador fique eternamente vinculado a esclarecer minúcias de questões já rechaçadas anteriormente.

\subsection{Enunciado 13}

O Enunciado 13 assim dispõe: “O art. 489, \ 1² IV, do CPC/2015 não obriga o juiz a enfrentar os fundamentos jurídicos invocados pela parte, quando já tenham sido enfrentados na formação dos precedentes obrigatórios".

Ao que parece, salvo melhor juízo, essa orientação atenta contra o âmago da própria reforma processual, já que abre a possibilidade ao julgador de evitar o exercício da técnica de distinguishing ou de overrruling. A formação dos precedentes obrigatórios é tão importante quanto a identificação, no caso concreto e diante dos fundamentos jurídicos invocados pelas partes, do respectivo precedente.

\subsection{Enunciado 19}

O Enunciado 19 assim dispõe:

A decisão que aplica a tese jurídica firmada em julgamento de casos repetitivos não precisa enfrentar os fundamentos já analisados na decisão paradigma, 
sendo suficiente, para fins de atendimento das exigências constantes no art. 489, \ $1^{\circ}$, do CPC/2015, a correlação fática e jurídica entre o caso concreto e aquele apreciado no incidente de solução concentrada.

Tanto quanto no item anterior, há de se ter em mente que fundamentação sucinta não se confunde com ausência de fundamentação. Assim, também nesse enunciado, percebe-se a construção de uma saída ao julgador com o fito de evitar o exercício da técnica de distinguishing ou de overrruling, de forma que sua aplicação merece toda cautela, sob pena de comprometer a desejada reforma do sistema jurídico-processual.

\subsection{Enunciado 47}

O Enunciado 47 assim dispõe: “O art. 489 do CPC/2015 não se aplica ao sistema de juizados especiais".

Fica evidente nessa orientação interpretativa que, apesar dos esforços em sentido contrário, os operadores do direito ainda encontram dificuldade em equacionar o razoável tempo de duração do processo com o dever de fundamentação das decisões. Sacrificar o segundo para enaltecer o primeiro é, sem dúvida, uma falácia com consequências desastrosas e severas. É um verdadeiro absurdo imaginar a aplicação de um enunciado nesse sentido, quando o dever de fundamentação é uma determinação constitucional, que apenas encontra regulamento na legislação ordinária.

\section{DEVER DE FUNDAMENTAÇÃO NO PROCESSO ADMINISTRATIVO TRIBUTÁRIO}

\subsection{Aplicação subsidiária do NCPC aos processos administrativos}

Inicialmente, destaca-se que o NCPC possui um dispositivo expresso (art. 15) no sentido de que "na ausência de normas que regulem processos eleitorais, trabalhistas ou administrativos, as disposições deste Código lhes serão aplicadas supletiva e subsidiariamente". Verifica-se, assim, que o NCPC determina de maneira expressa a sua aplicação como supletiva (ausência de norma reguladora na legislação do processo administrativo tributário e, portanto, sua total aplicação) e subsidiária (pequena regulamentação na legislação do processo administrativo tributário e, portanto, a complementação da regulamentação) ao processo administrativo tributário. 
Diante dessa constatação, parece ter sido solucionada a discussão sobre a juridicidade dos órgãos administrativos de julgamento, na medida em que, por disposição expressa, os processos administrativos deverão respeitar as normas processuais. Nesse sentido, os professores Paulo César Conrado e Rodrigo Dalla Pria $^{11}$ explicam que

Os órgãos de julgamento integrantes do contencioso administrativo tributário exercem, no desempenho de suas funções, atividade jurisdicional, e não propriamente administrativa; longe de construírem (ou reconstruírem) o crédito tributário administrativamente debatido, eles examinam a pretensão deduzida no instrumento de provocação que os impulsiona a agir (no mais das vezes, produzido pelo contribuinte). Sua atividade antes de vinculada à arrecadação (nada tendo, portanto, com a noção de "cobrança"), é marcada pela premissa da antiexacionalidade, vocábulo forjado na intenção de definir os instrumentos processuais destinados a avaliar se a exigibilidade de dado crédito tributário deve ou não subsistir. Como o judicial, o processo administrativo pode e deve ser visto como instrumento da jurisdição, portanto.

Por fim, faz-se necessário relembrar que a aplicação supletiva e subsidiária se dá apenas com relação às normas processuais, e não às procedimentais, posto que só as primeiras (ligadas ao princípio do devido processo legal) regulam a atividade jurisdicional.

\subsection{Dever de fundamentação no processo administrativo tributário}

Diante do anteriormente exposto, percebe-se que a aplicação supletiva e subsidiária do NCPC ao processo administrativo tributário, no tocante ao dever de fundamentação, é cogente; afinal, o dever de fundamentação é pressuposto do próprio exercício de jurisdição.

Sobre o tema verifica-se, por exemplo, a decisão da Câmara Superior de Recursos Fiscais (CSRF) do Conselho Administrativo de Recursos Fiscais (CARF), a qual no início do ano de 2016 proferiu decisão no seguinte sentido:

11 CONRADO, Paulo César; PRIA, Rodrigo Dalla. Aplicação do Código de Processo Civil ao processo administrativo tributário. In: CONRADO, Paulo César; ARAÚJO, Juliana Furtado Costa (Coord.). O Novo CPC e seu impacto no Direito Tributário. São Paulo: Fiscosoft, 2105. p. 250. 


\section{ASSUNTO: PROCESSO ADMINISTRATIVO FISCAL}

Ano-calendário: 2000

NULIDADE DE ACÓRDÃO DA TURMA A QUO. AUSÊNCIA DE FUNDAMENTAÇÃO.

Com base no inciso IX do art. 93 da Constituição Republicana de 1988 e nos arts. 131, 165 e 458, II, do CPC, é nulo, por ausência de fundamentação, o Acórdão no qual a maioria dos conselheiros acolher apenas a conclusão do voto do relator e não estiverem escritos os fundamentos adotados pela maioria dos conselheiros, em declaração de voto ou por reprodução, pelo relator, no seu voto e na ementa do acórdão, desses fundamentos majoritários. (Processo 16327.002142/2005-81, Acórdão 9101-002.179, Recurso Especial do Procurador, Cons. Rel. Rafael Vidal de Araujo, DJ: 19 jan. 2016)

De todo o exposto, não há como negar que a necessidade de fundamentação das decisões é claramente aplicável ao processo administrativo tributário, sendo, portanto, obrigatório que os órgãos administrativos de julgamento, como os judiciais, fundamentem suas decisões nos termos elucidados neste estudo, sob pena de inarredável nulidade.

\section{CONSIDERAÇÕES FINAIS}

Não se pode negar a suma importância de o poder judiciário e os tribunais administrativos proferirem decisões fundamentadas, posto que, agindo assim, além de respeitarem o dispositivo constitucional expresso sobre o tema e o NCPC, estarão julgando em conformidade com a democracia e com os princípios do contraditório, do devido processo legal e da duração razoável do processo.

Embora o dever de fundamentação do NCPC esteja em total harmonia com os princípios e os deveres constitucionais, percebe-se, na prática, que ainda há resistência quanto à sua aplicação. Assim, se torna imprescindível a necessidade de fomentar a discussão, especialmente aos advogados, cuja capacidade postulatória garante a provocação da jurisdição em oposição à inércia, visando melhorar a qualidade das demandas judiciais e administrativas tributárias e combater ativamente as decisões minimalistas.

A garantia de prevalência dessa garantia constitucional é, em última análise, a defesa do Estado Democrático de Direito, de forma que sua observação, como insistentemente defendido neste estudo, é inafastável, seja em processos judiciais (de toda e qualquer natureza), seja em processos administrativos (majoritariamente de natureza tributária). 
